\title{
Metabolic Fingerprinting of Citrus Cultivars and Related Genera Using HPLC and Multivariate Analysis
}

\author{
Tetsuya Matsukawa $^{1} \&$ Nobumasa Nito $^{1}$ \\ ${ }^{1}$ Kindai University, Japan \\ Correspondence: Tetsuya Matsukawa, Kindai University, Japan. E-mail: tmatsu@waka.kindai.ac.jp
}

Received: August 3, 2017

Accepted: September 19, 2017 Online Published: November 8, 2017

doi:10.5539/jps.v7n1p1

URL: https://doi.org/10.5539/jps.v7n1p1

\begin{abstract}
Citrus taxonomy is very complex and confusing, because of asexual reproduction and sexual compatibility between Citrus and related genera. Metabolic diversity was studied in Citrus, Poncirus and Fortunella cultivars by the high performance liquid chromatography technique combined with multivariate statistical analysis. Chromatograms obtained from cultivars of the same species showed similar elution profiles. These results suggested that metabolic profiles carry characteristics of hybrid origin. To confirm the similarities among the Citrus species and their cultivars, multivariate statistical analysis was applied to the chromatograms. According to hierarchical cluster analysis, all cultivars used in this study were divided into three major groups, which largely correspond to pummelo, mandarin and lemon. Hybrids were clustered together with their hybrid origin or their related cultivars. Our results indicated that the metabolic fingerprinting method provides an insight into the phylogenic relationships among Citrus species and cultivars.
\end{abstract}

Keywords: chemotaxonomy, Citrus, metabolic fingerprinting, secondary metabolite

\section{Introduction}

The true citrus fruit trees comprise six genera, i.e. Fortunella, Poncirus, Citrus, Microcitrus, Eremocitrus and Clymenia. Among these, the Citrus species is one of the most commercially important groups and has a wide diversity of related cultivars. However, Citrus taxonomy and phylogeny are very complex and confusing because of asexual seed reproduction and sexual compatibility between Citrus and related genera. Until the mid 1970s, studies on Citrus taxonomy were carried out based on morphological and geographical data, and numbers of classification systems were formulated. Among them, the classification systems formulated by Swingle (1943) and Tanaka (1969) have been widely accepted. However, these two widely accepted systems are based on different classification concepts. Swingle identified only 16 species, while Tanaka recognized 162 species. Later, Scora (1975) and Barret and Rhodes (1976) proposed that there are only three species in the subgenus Citrus, i.e. citron (Citrus medica L.), mandarin (Citrus reticulata Blanco) and pummelo (Citrus grandis (L.) Osbeck), and the other genotypes have originated by hybridization between these three true species. Recently, this three-species concept has been supported by many studies using biochemical and molecular markers, such as isozymes (Torres et al., 1978; Fang et al., 1993; Herrero et al., 1996), microsatellites (Fang and Roose, 1997; Fang et al., 1998) and nuclear (Ramadugu et al., 2013) and organellar genome analyses (Green et al., 1986; Yamamoto et al., 1993; Nicolosi et al., 2000; Carbonell-Caballero et al., 2015).

Since a variety of secondary metabolites present in higher plants apparently serve as defense compounds against environmental stresses, they are important for plant survival. Thus, the distribution of secondary metabolites appears to represent the adaptive characters that have been evolved through natural selection. Since secondary metabolites within the members of a family are often similar, their distribution of secondary metabolites could be used as one of the markers for phylogenetic and taxonomic classifications.

Early studies on Citrus chemotaxonomy based on secondary metabolites, were carried out using thin-layer chromatography (Albach and Redman, 1969; Tatum et al., 1974) and paper chromatography techniques (Dass et al., 1977, 1978; Grieve and Scora, 1980; Handa, 1988). These methods are effective for comparing patterns of pigment composition, but require visual estimation of the separated compounds for their quantification. Recently, high-performance liquid chromatography (HPLC) has been used for the separation and quantification of metabolites, and multivariate statistical methods have also been introduced for estimating similarities in chemical composition. Gayou et al. (1987) analyzed six polymethoxylated flavones in peel oils of six Citrus 
cultivars and applied a multivariate statistical analysis to sample classification. Kawaii et al. (1999) also quantitatively identified 24 flavonoids in fruits in order to determine the relationships among 66 Citrus species.

These studies focused on fruit metabolites because of their commercial importance. However, since leaves are a richer source of secondary metabolites in higher plants, metabolites in leaves should also be included in chemotaxonomic analysis. The previous authors purified metabolites, identified their chemical structures and determined their amounts. However, the requirement for the preparation of authentic compounds and baseline separation on HPLC limits the analysis to a narrow range of metabolites, and thus, restricsts their application for taxonomic analysis of a wide range of cultivars and species. Recently, metabolomic approaches using LC/MS and GC/MS techniques have been used for qualitative analysis (Sumner et al., 2003). These techniques have become powerful tool to gain comprehensive information of metabolites in plant materials. However, these techniques need expensive devises and specific software which handle a large amount of information produced by the devices. Moreover, since identification of metabolites depends on mass spectra databases, application of these techniques is limited to primary metabolites or secondary metabolites of model organisms. In order to provide the relationships between the different species based on secondary metabolites, we performed a comprehensive analysis of UV absorbing secondary metabolites such as flavonoids and coumarins, major compounds in citrus, in leaves by using conventional HPLC, and the elution profiles were applied to chromatographic pattern analysis based on multivariate statistical analysis.

\section{Materials and Methods}

\subsection{Plant Material}

The youngest and fully expanded leaves of 29 cultivars (Table 1) were harvested and collected from mature trees maintained in Yuasa Experimental Farm, Wakayama Prefecture, Japan. For minimize the environmental condition, all trees used in this study were grown in the same fields. Five biological replicates were collected for each species.

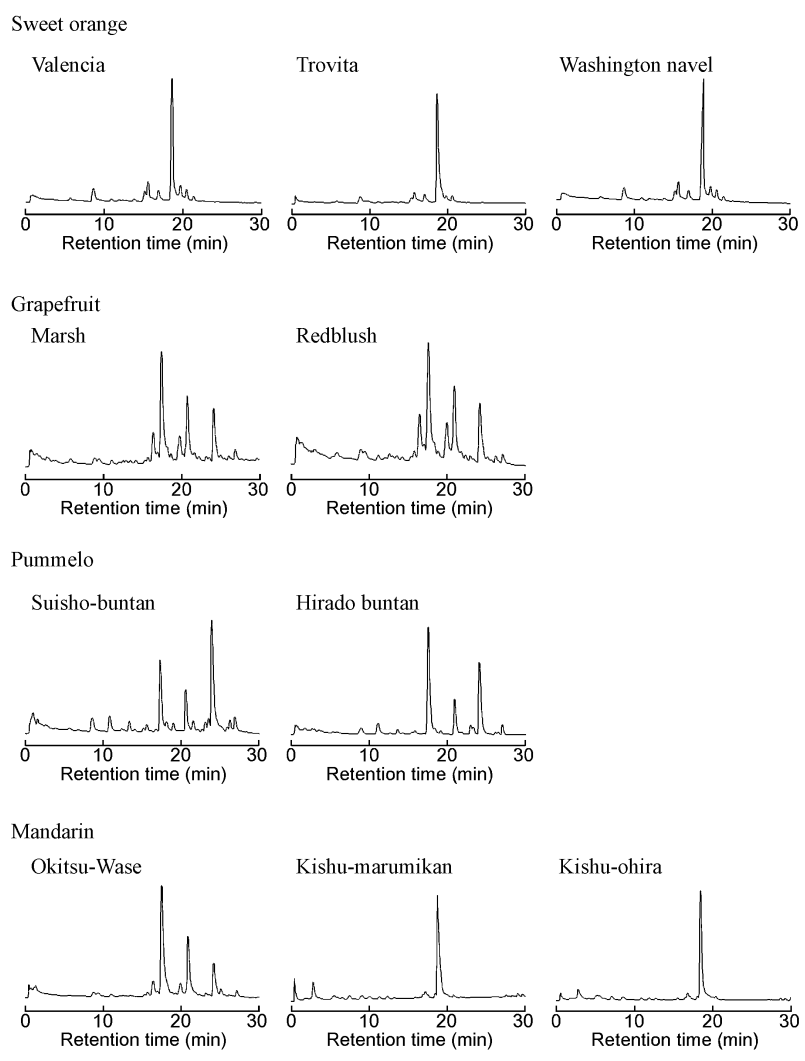



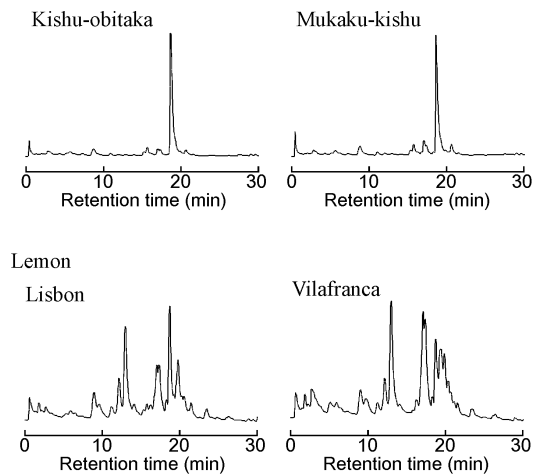

Others
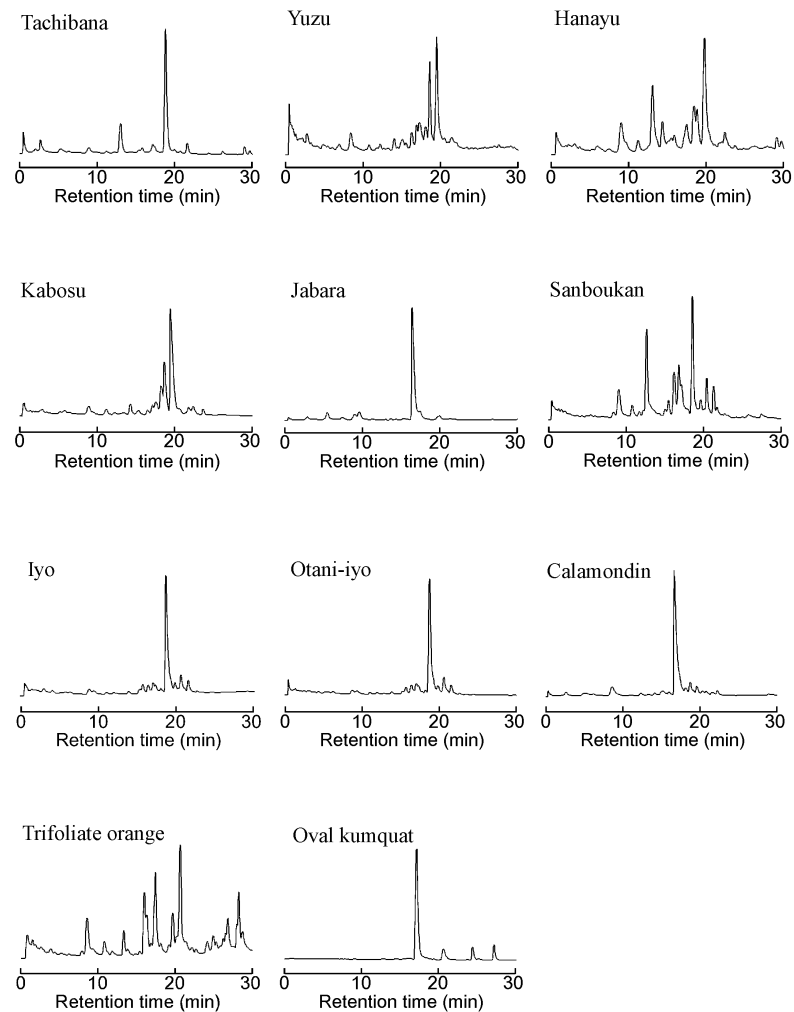

Oval kumquat

Hybrid
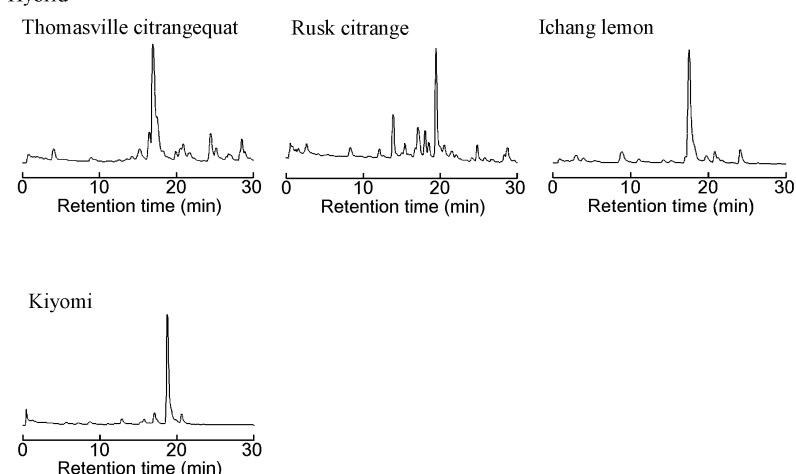

Figure 1. HPLC chromatograms of MeOH extracts obtained from mature leaves of Citrus and related genera. Elution of metabolites was monitored at $280 \mathrm{~nm}$ 
Table 1. Plant materials used in this study

\begin{tabular}{|c|c|c|}
\hline \multirow[b]{2}{*}{ Cultivar } & \multicolumn{2}{|l|}{ Scientific name $^{\mathrm{a}}$} \\
\hline & Swingle's system & Tanaka's system \\
\hline $\begin{array}{l}\text { Sweet orange } \\
\text { Trovita } \\
\text { Valencia } \\
\text { Washington }\end{array}$ & Citrus sinensis (L.) Osbeck & Citrus sinensis (L.) Osbeck \\
\hline \multicolumn{3}{|l|}{ Navel } \\
\hline $\begin{array}{l}\text { Grapefruit } \\
\text { Marsh } \\
\text { Redblush }\end{array}$ & C. paradisi Macf. & C. paradisi Macf. \\
\hline $\begin{array}{l}\text { Pummelo } \\
\text { Suisho buntan } \\
\text { Hirado buntan }\end{array}$ & C. grandis (L.) Osbeck & C. grandis (L.) Osbeck \\
\hline \multicolumn{3}{|l|}{ Mandarin } \\
\hline Okitsu Wase & C. reticulata Blanco & C. unshiu Marc. \\
\hline $\begin{array}{l}\text { Kishu } \\
\text { marumikan }\end{array}$ & $-\mathrm{b}$ & C. kinokuni Hort. ex. Tan. \\
\hline Kishu ohira & - & C. kinokuni Hort. ex. Tan. \\
\hline Kishu obitaka & - & C. kinokuni Hort. ex. Tan. \\
\hline Mukaku kishu & - & C. kinokuni Hort. ex. Tan. \\
\hline $\begin{array}{l}\text { Lemon } \\
\text { Lisbon } \\
\text { Villafranca }\end{array}$ & C. limon Osbeck & C. limon Osbeck \\
\hline \multicolumn{3}{|l|}{ Others } \\
\hline Tachibana & - & C. tachibana (Mak.) Tan. \\
\hline Yuzu & - & C. junos Sieb. ex. Tan. \\
\hline Hanayu & - & C. hanayu Sieb. ex. Tan. \\
\hline Kabosu & C. aurantium & C. sphaernocarp Hort. ex. Y. Tan. \\
\hline Jabara & - & C. jabara Hort. ex. Y. Tanaka \\
\hline Samboukan & - & C. sulcata Hort. ex. Takahashi \\
\hline Iyo & - & C. iyo Hort. ex. Tan. \\
\hline Ohtani iyo & - & C. iyo Hort. ex. Tan. \\
\hline Calamondin & - & C. madurensis Lour. \\
\hline 'Oval' kumquat & Fortunella margarita Swingle & Fortunella margarita Swingle \\
\hline $\begin{array}{l}\text { Trifoliate orange } \\
\text { Hybrid }\end{array}$ & Poncirus trifoliata Raf. & Poncirus trifoliata Raf. \\
\hline Thomasville & \multicolumn{2}{|c|}{ F. margarita $\times(P$. trifoliata $\times C$. sinensis $)$} \\
\hline Rusk & \multicolumn{2}{|c|}{ C. sinensis $\times P$. trifoliata } \\
\hline Ichang lemon & \multicolumn{2}{|l|}{ C. ichangensis $\times C$. grandis } \\
\hline Kiyomi & \multicolumn{2}{|l|}{ C. unshiu $\times$ C. sinensis } \\
\hline
\end{tabular}

a Botanical names are based on Swingle's system. In addition to this system, the botanical names of Tanaka's system are mentioned for species indigenous to Japan.

$\mathrm{b}$ not identified

\subsection{Extraction of Secondary Metabolites}

Citrus leaves were frozen in liquid nitrogen and ground to a fine powder. The powder was extracted with 5 volumes of methanol, a suitable solvent for extraction of semi-polar metabolites (Ballester et al., 2016), and centrifuged at $12,000 \mathrm{~g}$ for $15 \mathrm{~min}$. An aliquot of the supernatant was filtered, and the filtrate was subjected to HPLC analysis.

\subsection{HPLC Condition}

The extract was analyzed by an Shimadzu 10A system (Shimadzu, Kyoto, Japan) with a 4.6 i.d. $\times 50 \mathrm{~mm}$ Cosmosil 3C18 AR-II column (Nacalai tesque, Kyoto, Japan). A two solvent system was used to generate the mobile phase — solvent A was $0.1 \%$ acetic acid solution and solvent B was $\mathrm{MeOH}$. The flow rate was $1.2 \mathrm{ml} / \mathrm{min}$. 
The mobile phase at the beginning of the analysis was $18 \% \mathrm{~B}$ in A. After the injection of the extract, the ratio was maintained for $5 \mathrm{~min}$, followed by a linear gradient from $18 \%$ to $38 \%$ B in A in $15 \mathrm{~min}$. Subsequently, a 10 min linear gradient from $38 \%$ to $58 \%$ B in A was applied. The elution of secondary metabolites was monitored at $286 \mathrm{~nm}$.

\subsection{Statistical Analysis}

To apply a multivariate analysis to the chromatogram profile, raw chromatograms obtained from each run were scanned and transformed to digital (x, y) data by a digitizing program Un-Scan-It (Silk Scientific, Inc., UT). All the transformed data were imported to the multivariate data analysis program Pirouette 3.11 (Infometrix, Inc., WA). The elution profiles of five replicates were averaged, and the differences in the elution time of each run were adjusted and aligned with reference to the co-chromatogram data of each sample. The aligned data set was used for hierarchical cluster analysis (HCA). The multivariate measure of the distance between each cluster was based on Euclidean distance, and the cluster was linked based on the incremental method.

\section{Results and Discussion}

\subsection{HPLC Chromatograms}

All the leaf samples used in this study were harvested from the same field on the same day, and thus, were grown under the same climatic conditions. The leaf samples were extracted with methanol and subjected to reverse phase HPLC analyses. The applied gradient system covers the major UV active compounds, including flavonoids, coumarins and phenylpropanoids.

As shown in Figure. 1, the chromatograms obtained from cultivars of the same species showed largely similar elution profiles. In the chromatograms of sweet orange (C. sinensis) cultivars, all the major peaks were common to the cultivars and were of a similar size. Almost all peaks were common to the two cultivars of grapefruit $(C$. paradisi), and in pummelos (C. grandis), the three major peaks detected in 'Suisho buntan' were also detected in 'Hirado buntan'. In contrast, mandarin cultivars showed heterogeneity in the elution profiles. 'Okitsu Wase' showed three major peaks, which were not detected in the other mandarin cultivars. On the other hand, the largest peak commonly detected in 'Kishu marumikan', 'Kishu ohira', 'Kishu obitaka' and 'Mukaku Kishu' was absent in 'Okitsu Wase'. 'Okitsu Wase' are considered to belong to satsuma mandarins, while others are kishu mandarins, and thus, the differences in elution profiles reflect the difference between satsuma and kishu. In the chromatograms of the two lemon $(C$. limon) cultivars, many peaks overlapped each other. The similarity between the elution profiles of the two cultivars was observed, although the intensity of each peaks was different among two species.

On comparing the elution profiles of the species, a similarity was detected between the elution profiles of grapefruit and pummelo cultivars. The retention times of the three major peaks in the grapefruit cultivars were completely consistent with those of the two pummelo cultivars, although the relative sizes of the peaks in the two species were different. The elution profile of the mandarin cultivar 'Okitsu Wase' (C. unshiu) also resembled those of the other species.

The elution profile of 'Kiyomi' was quite similar to those of the sweet orange cultivars. 'Kiyomi' is the artificial hybrid of 'Miyagawa Wase' (C. unshiu) and 'Trovita' (C. sinensis) (Nishiura et al., 1983). Thus, it was found that the metabolic character of 'Trovita' was dominantly inherited through the screening and breeding program.

Other cultivars showed cultivar-specific chromatograms. Many of these cultivars are thought to be indigenous to Japan and their origin is still obscure. Among them, cultivars classified as C. iyo ('Iyo' and 'Ohtani iyo') showed similar elution profiles. Their profiles were also similar to those of the four mandarin cultivars 'Kishu marumikan', 'Kishu ohira', 'Kishu obitaka' and 'Mukaku Kishu', suggesting that these two groups might have originated from the same ancestor.

\subsection{Hierarchical Cluster Analysis}

To confirm the similarities among the Citrus species and their cultivars, the elution profiles were subjected to the hierarchical cluster analysis. Chromatograms were converted to 1000 data points, and the data was clustered by the application of an incremental linkage method based on Euclidean distance. Figure. 2 shows the dendrogram constructed by using the hierarchical cluster analysis.

Based on this dendrogram, the analyzed cultivars were divided into three major groups. The first group contained three cultivars of sweet orange ( $C$. sinensis), and the four mandarin cultivars namely, 'Kishu marumikan', 'Kishu ohira', 'Kishu obitaka' and 'Mukaku Kishu' (C. kinokuni). In addition, the two C. iyo cultivars, 'Iyo' and 'Ohtani iyo' as well as the other Citrus cultivars 'Tachibana' (C. tachibana), 'Kabosu' (C. 
sphaernocarp), 'Yuzu' (C. junos), 'Hanayu' (C. hanayu), 'Calamondin' (C. madurensis) and the two hybrids 'Kiyomi' and 'Rusk' citrange were included in this group. The second group consisted mainly of the grapefruit and pummelo cultivars. 'Oval' kumquat (F. margarita) and trifoliate orange (C. trifoliata) were also clustered in the second group. The third group contained cultivars of lemon (C. limon) and 'Jabara' (C. jabara). Barret and Rhodes (1976) postulated that the diverse genotypes in the genus Citrus originated from only three species, namely, mandarin $(C$. reticulata), pummelo $(C$. grandis) and citron $(C$. medica). The three groups observed in our dendrogram largely corresponded to the mandarin, pummelo and citron groups, supporting the three species concept (Scora, 1975; Barret and Rhodes, 1976; Nicolosi et al., 2000; Carbonell-Caballero et al., 2015).

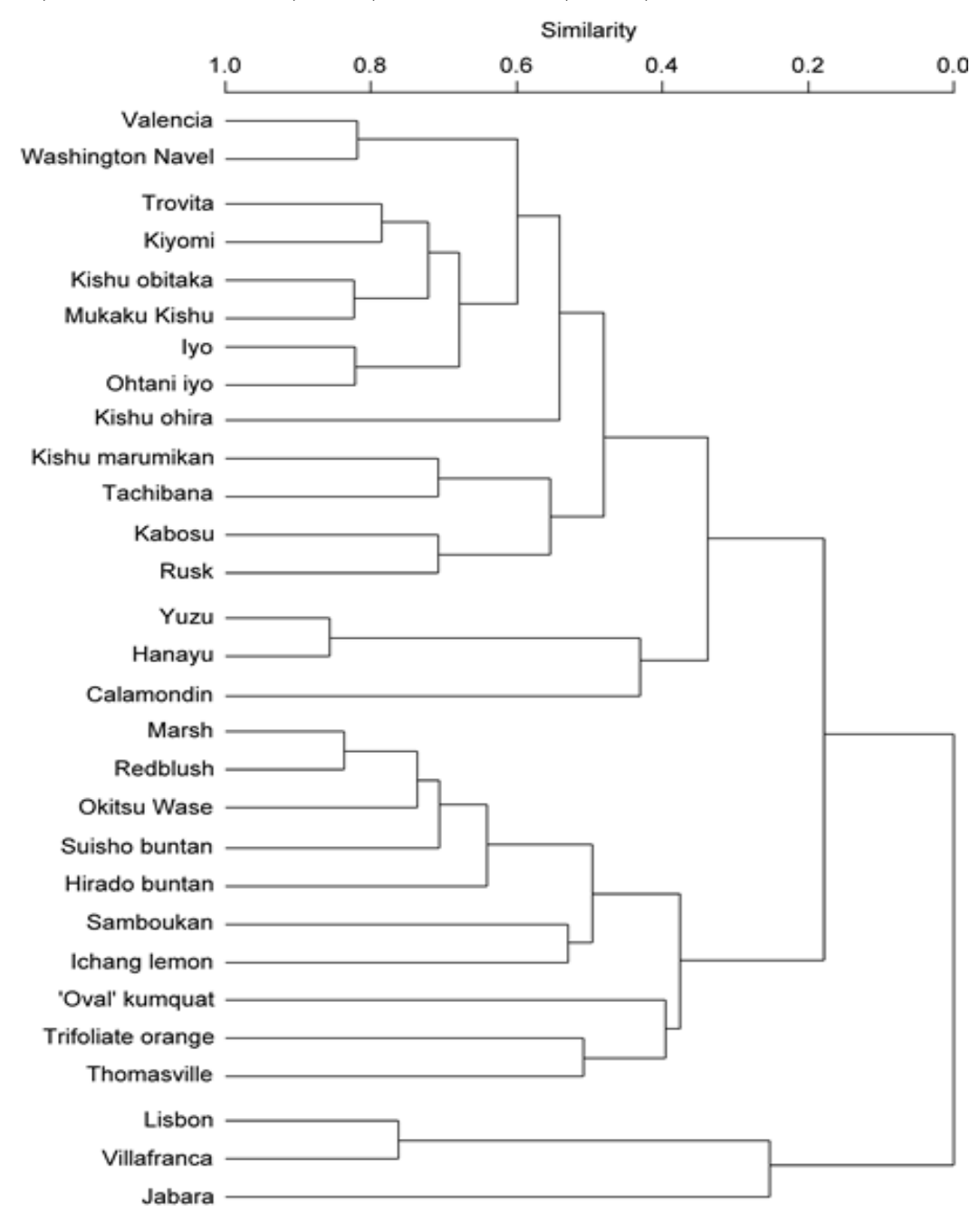

Figure 2. Dendrogram of 29 cultivars of Citrus and related genera obtained by hierarchical cluster analysis of HPLC chromatogram data

The first group was divided into two subgroups; the first subgroup was composed mainly of sweet orange cultivars and four mandarin cultivars, and the other subgroup was composed of the cultivars 'Yuzu', 'Hanayu' and 'Calamondin'. 'Iyo' and 'Ohtani iyo' were included in the first subgroup together with the sweet orange cultivars. Since it has been suggested that 'Iyo' and 'Ohtani iyo' are natural tangors (Tanaka, 1954), their close relationship with sweet oranges is reasonable. 'Kishu marumikan', 'Kishu ohira', 'Kishu obitaka' and 'Mukaku Kishu' ( $C$. kinokuni) were also clustered in the first subgroup. The phylogenic relationship between $C$. kinokuni and the other cultivars is unclear. The close relationship between $C$. kinokuni and $C$. sinensis suggests that $C$. reticulata was involved in the differentiation of $C$. kinokuni because $C$. sinensis have been thought to be of predominantly the C. reticulata genotype introgressed with genes from C. grandis (Barrett and Rhodes, 1976; Nicolosi et al., 2000). Moreover, C. sinensis is now thought to originate from backcross hybrid between pummelo and mandarin (Xu et al., 2013). The phylogenic relationship between 'Tachibana' and 'Kabosu' and sweet oranges may suggest the involvement of C. reticulata in the differentiation of these cultivars. 'Yuzu', 
'Hanayu' and 'Calamondin' were clustered as the second subgroup in the first group, suggesting the introgression of traits of $C$. reticulata into the cultivars.

'Kiyomi' was closely related to orange cultivars, such as 'Valencia', 'Trovita' and 'Washington Navel'. 'Kiyomi' is the artificial hybrid of 'Miyagawa Wase' unshu (C. unshiu) and 'Trovita' orange (C. sinensis) (Nishiura et al., 1983). Thus, the clustering of 'Kiyomi' with 'Trovita' reflects the origin of 'Kiyomi' and the metabolic characteristics of 'Trovita' may be predominantly inherited in this hybrid. Among sweet orange cultivars 'Kiyomi' with 'Trovita' showed the closest relationship, which indicates the utility of the hierarchical cluster analysis of elution profiles of the Citrus cultivars.

The second group consists of 11 cultivars and is divided into two subgroups. The first subgroup includes grapefruit ( $C$. paradisi) cultivars, the mandarin cultivar 'Okitsu Wase' ( $C$. unshiu), pummelo ( $C$. grandis) cultivars, 'Ichang lemon' ( $C$. ichangensis $\times$ unknown cultivar of $C$. grandis) and 'Samboukan' ( . sulcata). It has been suggested that grapefruit is derived from a sweet orange and pummelo hybrid (Scora, 1975; Barrett and Rhodes, 1976; Scora et al., 1982 Scora and Kumamoto, 1983; Nicolosi et al., 2000). The strong similarity between grapefruit cultivars and those of pummelo was indicated in our analysis, whereas no similarity was observed between grapefruit and sweet oranges. This is consistent with previous studies that indicate the close relationship between grapefruit and pummelo (Swingle and Reece, 1967; Handa, 1988). The close similarity between satsuma mandarin (C. unshiu) and pummelos and grapefruits was an unexpected result. Satsuma mandarin is believed to have originated in Japan as a chance seedling from a fruit or to have been imported from China (Swingle and Reece, 1967). Swingle (1943) identified it as one of the C. reticulata hybrids, while Tanaka (1977) recognized it as one of the Citrus species. In this study, metabolic patterns and statistical analysis showed a high similarity between satsuma mandarin and $C$. grandis, suggesting that some pummelo-type species were involved in the origin of satsuma mandarin. Tanaka (1932) named Ichang lemon $C$. wilsonii and stated that this species unquestionably had $C$. junos as one parent and that it appeared to be a cultigen that had originated as a chance seedling. On the contrary, Swingle and Reece (1967) stated that there was no valid reason for considering this plant as a botanical species since it is undoubtedly a chance hybrid of $C$. ichangensis. Based on our results, the characteristics of $C$. grandis might be strongly appeared. 'Samboukan' is indigenous to Japan, and its origin and its related species or cultivars are unknown. Our results suggest that pummelos were involved in the origin or differentiation of this cultivar.

The second subgroup contains 'Oval' kumquat ( $F$. margarita), trifoliate orange ( $P$. trifoliata) and 'Thomasville' citrangequat. However, 'Oval' kumquat cluster showed low similarity to the Poncirus cluster. 'Thomasville' citrangequat is an artificial trigeneric hybrid of 'Oval' kumquat ( $F$. margarita) and 'Wiltis' citrange ( $P$. trifoliata $\times C$. sinensis). Our results indicate that the metabolic profile of 'Thomasville' citrangequat is closer to $P$. trifoliata, suggesting that the metabolic character of $P$. trifoliata is dominantly inherited.

The last group is composed of lemon cultivars (C. limon) and 'Jabara' (C. jabara). Based on morphological characteristics, lemon was supposed to be a hybrid of citron $(C$. medica) and lime (C. aurantifolia) (Swingle, 1943; Malik et al., 1974; Scora, 1975). Barrett and Rhodes (1976) reported that lemon is a trihybrid of citron, pummelo and Microcitrus and had a higher proportion of citron genes. Torres et al. (1978) suggested that sour orange (C. aurantium) and lime are of hybrid origin. Based on the molecular marker data, Yamamoto et al. (1993) suggested that lemon is a hybrid of pummelo and citron, while Nicolosi et al. (2000) reported that lemon originated from citron and lime. Other report suggested that lemon originated from the complex hybridization of C. maxima, C. reticulata and C. medica (Clurk et al., 2014). Lemon cultivars clustered separately from the mandarin and pummelo clusters because of the strong influence of citron. 'Jabara' is indigenous to Japan and is cultivated in a limited area. Its origin is obscure and is thought to be a cultivar related to 'Yuzu' or 'Kunembo' mandarin. In order to determine the origin of this unique cultivar, the analysis of lime and citron will be necessary.

In summary, our chemotaxonomic results were broadly in accordance with the three-species concept. Although our method cannot provide the structural information of individual peaks, the method using conventional HPLC combined with multivariate statistical analysis was proven to be a simple and powerful tool for providing new insights into the phylogenic relationship among the Citrus cultivars and hybrids. Several questions and unexpected results have to be investigated. Further studies with a large number of cultivars and species would provide us with a deeper understanding of Citrus phylogeny and taxonomy.

\section{References}

Albach, R. F., \& Redman, G. H. (1969). Composition and inheritance of flavanones in citrus fruit. Phytochemistry, 8, 127-143. https://doi.org/10.1016/S0031-9422(00)85805-7 
Ballester, A. R., Tikunov, Y., Malthoff, J., Grandillo, S., Viquez-Zamora, M., de Vos, R., de Maagd, R. A., van Heusden, S., \& Bovy, A. G. (2016). Identification of loci affectinf accumulation of secondary metabolites in tomato fruit of a Solanum lycoperisicum x Solanum chmielewskii introgression line population. Front. Plant Sci. 7, 1428. https://doi.org/10.3389/fpls.2016.01428

Barrett, H. C., \& Rhodes, A. M. (1976). A numerical study of affinity relationships in cultivated Citrus and its close relatives. Systematic Botany, 1, 105-136. https://doi.org/10.2307/2418763

Carbonell-Caballero, J., Alonso, R., Ibañez, V., Terol, J., Talon, M., \& Dopazo, J. (2015). A phylogenetic analysis of 34 chloroplast genomes elucidates the relationships between wild and domestic species within the genus Citrus. Mol. Biol. Evol. 32, 2015-2035. https://doi.org/10.1093/molbrv/msv

Clurk, F., Ancillo, G., Ollitrault, F., Perrier, X., Jacquemoud-Collet J. P., Gracia-Lor, A., Navvaro, L., \& Ollitrault, P. (2015). Nuclear species-diagnostic SNP markers mined from 454 amplicon sequencing reveal admixture genomic structure of modern Citrus varieties. Plos One, 10, e0125628. https://doi.org/10.1371/journal.pone.0125628

Dass, H. C., Randhawa, G. S., \& Parakash, D. (1977). Phylogenetic studies in Citurus reticulata and related types. Euphytica, 26, 805-810. https://doi.org/10.1007/BF00021710

Dass, H. C., Randhawa, G. S., \& Parakash, D. (1978). Leaf flavonoid patterns of some important citrus species. Indian Journal of Experimental Biology, 16, 62-65.

Fang, D. Q., Krueger, R. R., \& Roose, M. L. (1998). Phylogenic relationships among selected Citrus germplasm accessions revealed by inter-simple sequence repeat (ISSR) markers. Journal of the American Society for Horticultural Science, 123, 612-617.

Fang, D. Q., \& Roose, M. L. (1997). Identification of closely related citrus cultivars with inter-simple sequence repeat markers. Theoretical Applied Genetics, 95, 408-417. https://doi.org/10.1007/s1220050577

Fang, D. Q., Zhang, W. C., \& Xiao, S. Y. (1993). Studies on taxonomy and evolution of Citrus and its related genera by isozyme analysis. Acta Phytotaxonomica Sinica, 31, 329-352.

Gayou, E. M., Bianchini, J. P., \& Randriamiharisoa, R. P. (1987). Orange and mandarin peel oils differentiation using polymethoxylated flavone composition. Journal of Agricultural and Food Chemistry, 35, 525-529. http://dx.doi.org/10.jf00076a021

Green, R. M., Vardi, A., \& Galun, E. (1986). The plastome of Citrus. Physical map, variation among Citrus cultivars and species, and comparison with related genera. Theoretical Applied Genetics, 72, 170-177. https://doi.org/10.1007/BF00266989

Grieve, C. M., \& Scora, R. W. (1980). Flavonoid distribution in the Aurantioideae (Rutaceae). Systematic Botany, 5, 39-53. http://dx/doi.org/10.2307/2418734

Handa, T. (1988). Numerical and chemical taxonomy of genus Citrus and some related genera in Aurantioideae. Memoirs of Institute of Agriculture and Forestry, the University of Tsukuba, 4, 143-257.

Herrero, R., Asins, M. J., Carbonell, E. A., \& Navarro, L. (1996). Genetic diversity in the orange subfamily Aurantioideae. I. Intraspecies and intragenus genetic variability. Theoretical Applied Genetics, 92, 599-609. https://doi.org/10.1007/BF00224564

Kawaii, S., Tomono, Y., Katase, E., Ogawa, K., \& Yano, M. (1999). Quantitation of flavonoid constituents in Citrus Fruits. Journal of Agricultural and Food Chemistry, 47, 3565-3571. http://dx.doi.org/10.1021/jf990153

Malik, M. N., Scora, R. W., \& Soost, R. K. (1974). Studies on the origin of the lemon. Hilgardia 42, 361-382.

Nicolosi, E., Deng, Z. N., Gentile, A., La Malfa, S., Continella, G., \& Tribulato, E. (2000). Citrus phylogeny and genetic origin of important species as investigated by molecular markers. Theoretical Applied Genetics, 100, 1155-1166. https://doi.org/10.1007/s001220051419

Nishiura, M., Shichijo, T., Ueno, I., Iwamasa, M., Kihara, T., Yamada, Y., Yoshida, T., \& Iwasaki, T. (1983). New citrus cultivar 'Kiyomi' tangor. Bulletin of the Fruit Tree Research Station. Series B, 10, 1-9.

Ramadugu, C., Pfeil, B. E., Keremane, M., Lee, R. F. Maureira-Butler, I. J., Roose, M. L. (2013) A six nuclear gene phylogeny of Citrus (Rutaceae) taking into account hybridization and lineage sorting. Pols One, 8 , e68410. https://doi.org/10.1371/journal.pone.0068410

Scora, R. W. (1975). On the history and origin of Citrus. Bulletin Torrey Botanical Club, 102, 369-375. 
Scora, R. W., \& Kumamoto, J. (1983). Chemotaxonomy of the genus Citrus. In: Chemistry and chemical taxonomy of the Rutales. Waterman PG and Grundon MF (ed.) Academic Press, London; 343-352.

Scora, R. W., Kumamoto, J., Soost, R. K., \& Nauer, E. M. (1982). Contribution to the origin of the grapefruit, Citrus paradisi. Systematic Botany, 7, 170-177. hppt://dx.doi.org/10.2307/2418325

Swingle, W. T. (1943). The botany of Citrus and its relatives of the orange subfamily. In: The citrus industry, Vol. I, (Webber HJ, Batchelor LD eds.). University of California Press, Berkley, LA, pp. 190-430.

Swingle, W. T., \& Reece, P. C. (1967). The botany of Citrus and its wild relatives. In: The citrus industry, Vol. I, (Reuther W, Webber HJ, Batchelor LD, eds). University of California Press, Berkley, LA, pp. 190-430.

Sumner L. W., Mendes P., \& Dixon R. A. (2003). Plant metabolomics: large scale phytochemistry in the functional genomics era. Phytochemistry, 62, 817-836. https://doi.org/10.1016/S0031-9422(02)00708-2

Tanaka, T. (1932). Citrus wilsonii species nova. Memoir of Tanaka Citrus Experiment Station, 1, 37-38.

Tanaka, T. (1954). Species problem in Citrus (Revisio aurantiacearum IX). Japan Society for the Promotion of Science, Ueno, Tokyo, 152.

Tanaka, T. (1969). Misunderstanding with regards citrus classification and nomenclature. Bulletin of the University of Osaka Prefecture Series B, 21, 139-145.

Tanaka, T. (1977). Fundamental discussion of Citrus classification. Studia Citrogia, 14, 1-6.

Tatum, J. H., Berry, R. E., \& Hearn, C. J. (1974). Characterization of Citrus cultivars and separation of nucellar and zygotic seedlings by thin layer chromatography. Proceedings of the Forida State Horticultural Society, 87, 75-81.

Torres, A. M., Soost, R. K., \& Diedenhofen, U. (1978). Leaf isozymes as genetic markers in Citrus. American Journal of Botany, 65, 869-881

Xu, Q., Chen, L. L., Ruan, X., Chen, D., Zhu, A., ... Ruan, Y. (2013) the draft genome of sweet orange (Citrus sinensis). Nature Genetics, 45, 59-66. https://doi.org/10.1038/ng.2472

Yamamoto, M., Kobayashi, S., Nakamura, Y., \& Yamada, Y. (1993). Phylogenic relationships of Citrus revealed by RFLP analysis of mitochondrial and chloroplast DNA. Japanese Journal of Breeding, 43, 355-365.

\section{Copyrights}

Copyright for this article is retained by the author(s), with first publication rights granted to the journal.

This is an open-access article distributed under the terms and conditions of the Creative Commons Attribution license (http://creativecommons.org/licenses/by/4.0/). 